Perspective Within a Client-Centered and Pluralistic Therapy Framework

T. Ward \& K. Hogan

Pragmatic Case Studies in Psychotherapy, http://pcsp.libraries.rutgers.edu

Volume 11, Module 1, Article 5, pp. 55-64, 03-01-15 [copyright by authors]

Response to Commentaries on Using Client-Centered Psychotherapy

Embedded Within A Pluralistic Integrative Approach to Help a Client With Executive Dysfunction: The Case of "Judith"

\title{
The Case of "Judith": Reflections on Combining a Psychoneurological Perspective Within a Client-Centered and Pluralistic Therapy Framework
}

\section{TONY WARD ${ }^{\mathrm{a}, \mathrm{c}}$ \& KEVIN HOGAN ${ }^{\mathrm{b}}$}

${ }^{\mathrm{a}}$ University of the West of England, Bristol, England

${ }^{\mathrm{b}}$ Newman University, Birmingham, England

${ }^{\mathrm{C}}$ Correspondence regarding this article should be addressed to Tony Ward, Department of Health and Social Sciences, University of the West of England, Frenchay Campus, Bristol, BS16 1QY.

Email:tony.ward@uwe.ac.uk

Acknowledgement. An earlier version of this case study was presented at the annual conference of the British Psychological Society’s Division of Counselling Psychology, held at the University of Warwick, July, 2009.

\begin{abstract}
In this article, we respond to three commentaries by King (2015), Hyer and Brandon (2015), and Webb (2015) concerning our case study of Judith (Ward and Hogan, 2015). We organize our response in terms of five themes. First we discuss the positive features of the case study that were identified, specifically, viewing Judith's case as a successful example of combining the client-centered approach with cognitive training. Second, we consider the various ideas put forward about why the case was successful. For example, Hyer and Brandon suggest that the client-centered approach was the essential catalyst that helped Judith effectively utilize the cognitive training. Third we consider an issue common across the three commentaries, namely, the possible utility of additional neuropsychological testing and medical evidence. We acknowledge that such additional information might have been useful, but question its congruence with Cooper's and McLeod's (2011) "pluralistic psychotherapy" model that we employed, and the likely real-term benefits to the client. Fourth, we review the questions raised by the commentaries that remain unanswered about this case. We suggest that despite not being able to be precise about the severity of Judith's head injury, it is clear that a significant injury did occur, resulting in considerable disruption Judith's work and family life. Finally, we consider what the overall contribution of Judith's case study might be. We conclude by agreeing with King (2015) that, because cases like Judith's can derive great benefit from therapy, considerably more resources should be available for clients like her.
\end{abstract}

Key words: client centered therapy; pluralism; trauma; head injury; clinical case study; case study 
Perspective Within a Client-Centered and Pluralistic Therapy Framework

T. Ward \& K. Hogan

Pragmatic Case Studies in Psychotherapy, http://pcsp.libraries.rutgers.edu

Volume 11, Module 1, Article 5, pp. 55-64, 03-01-15 [copyright by authors]

\section{WHAT WERE THE POSITIVE FEATURES OF THE WORK WITH JUDITH?}

We appreciate the interesting, wide-ranging, and thoughtful commentaries on our case of Judith by King (2015), Hyer and Brandon (2015), and Webb (2015), and we welcome the opportunity to respond. As a start, we note that all three commentaries identify positive features of the work with Judith. King suggests that the case shows how a combination of client-centered therapy and cognitive rehabilitation techniques can lead to emotional growth and positive psychological results. He also views the case as illustrating the richness and complexity of neuropsychological work.

Webb also comments on the integrative, context-sensitive approach, and suggests the case demonstrates the value of higher-order therapies for people with neuropsychological weaknesses. Webb also suggests that the case illustrates the usefulness of ecological data as an adjunct to neuropsychological data. In the case of deficits in executive processes, this seems to us a very significant point, which we will elaborate on below in the section on neuropsychological assessment.

Hyer and Brandon echo these previous sentiments, suggesting that the case illustrates the value of combining "tried and true” psychotherapies, i.e., the client-centered approach, with cognitive training. They suggest that this combination encompasses "validating and actualizing methods promoting growth".

To summarize the positive features across the three commentaries, it seems that the work with Judith is perceived to have been very successful, with many best-practice components, including the combination of client centered therapy with cognitive training, conducted with sensitivity to the client's contexts and needs.

\section{WHY WAS THE WORK WITH JUDITH SUCCESSFUL?}

The three commentaries each speculate on why the work with Judith was successful, but here their accounts diverge somewhat.

King suggests that the positive outcomes in Judith's case were only evident after the addition of the cognitive rehabilitation and social support measures. We would acknowledge that these were vital ingredients in the overall package. However, Hyer and Brandon see this differently. They view the client-centered approach, which was strongly evident at the outset and which continued alongside the rest of the work, as having been the essential catalyst for the success of the later work. We would strongly agree with the Hyer and Brandon view. Because Judith felt valued and accepted she was able to re-experience and examine her emotions and anxieties, and come to reflect on and re-evaluate her predicament. This allowed Judith to get in contact with her feelings of abandonment and hopelessness, but also to identify other feelings. Initially this emerged as intense anger, followed by the desire to somehow carry on and find out how to cope with all the new demands she now needed to face. This was the point at which other 
Perspective Within a Client-Centered and Pluralistic Therapy Framework

T. Ward \& K. Hogan

Pragmatic Case Studies in Psychotherapy, http://pcsp.libraries.rutgers.edu

Volume 11, Module 1, Article 5, pp. 55-64, 03-01-15 [copyright by authors]

goals could naturally emerge, such as the need to be able to deal with household matters and paperwork.

Consistent with our view above, Hyer and Brandon suggest that client-centered approaches have been shown to work with trauma in the past (Hyer, 1994). They go on to speculate about the mechanism of action, suggesting that perhaps client-centeredness works with trauma as a kind of exposure therapy. They wonder to what extent might client-centered therapy evoke aspects of other established therapies, such as acceptance and commitment therapy. These are interesting questions, which could be further explored using in-depth session analysis and comparison with sessions carried out by other therapists. Such speculations seem reasonable to us, since our experience has been that client-centered therapy sessions can often feel like sessions that would fit quite happily within other frameworks, e.g. traumatized clients who are engaging in re-processing. The difference is that in client-centered therapy, the client rather than the therapist sets this direction for themselves, presumably motivated by the actualizing tendency.

Although King suggests that the cognitive rehabilitation was the more significant ingredient, he does acknowledge that there is a role for client centered-therapy in helping people after head injury ask and adapt to fundamental questions about themselves (Gracey et al, 2008). However, he concludes that such an approach cannot be sufficient, and that neuro-psychotherapy (Prigatano, 1986) will generally be required. We would agree and believe that this is evident in our work with Judith, which is an integration of the client centered-approach with cognitive training. We believe the latter component to be consistent with Prigatano's (1986) notion of neuro-psychotherapy. However, we would not privilege one aspect of the work above another, and as we suggested above, we believe that the client-centered approach was crucial in allowing Judith to process her emotional trauma initially, so that she could then move on and benefit from some of the more practical, behavioral, problem-focused work that came later.

Webb describes in considerable detail the likely neurological consequences of brain damage followed by long periods of stress. She conceives of psychotherapy as a neurobiological intervention, likely to have positive benefits in terms of cell viability and increased plasticity. We very much appreciate this perspective. We agree that there is great utility in explaining psychological interventions in neuro-scientific terms, and we believe this approach will have great potential in the future, especially if it can add further to the evidence base of what is effective.

In our case study, we suggested that psychotherapy could be adapted for use with neurological populations, based on our previous work with Myalgic Encephalopathy (ME) (Ward and Hogan, 2009). King disputes the relevance of this prior experience, noting that many clinicians would not see ME as a neurological condition. However, in our clinical experience and in our reading of the recent literature, we would conclude that there is an increasing group of clinicians and researchers who accept that ME is a genuine physical condition, rooted in pathophysiology. We are inclined towards the view of the International Consensus Group (Carruthers et al, 2011) that there is a subset of the ME population for whom there is good 
Perspective Within a Client-Centered and Pluralistic Therapy Framework

T. Ward \& K. Hogan

Pragmatic Case Studies in Psychotherapy, http://pcsp.libraries.rutgers.edu

Volume 11, Module 1, Article 5, pp. 55-64, 03-01-15 [copyright by authors]

evidence of pathophysiology (e.g. Lorusso et al, 2009) and neurological consequences (Cook et al, 2001). For this reason the consensus group prefer the term Myalgic Encephalomyelitis.

In our experience, severely affected clients with $\mathrm{ME}$ can have significant and pronounced information-processing deficits, often accompanied by working memory deficits and sometimes word finding difficulties. Furthermore, such difficulties do not, in our experience, preclude the possibility of therapy. Moreover, in our experience the sort of psychogenic view of ME to which King refers can lead to some profoundly negative experiences for clients with ME at the hands of therapists and other health workers (Ward et al, 2008). Finally on this topic, we would point out that in our trial of a client-centered approach for people with ME (Ward and Hogan, 2009), a number of the clients were coming to terms with issues of quite profound trauma, often related to significant and crushing losses. As with Judith, the client-centered approach was sufficient for the task.

\section{SHOULD THERE HAVE BEEN MORE NEUROPSYCHOLOGICAL ASSESSMENT?}

The three commentaries on Judith's case all make the point that the amount of traditional, neuropsychological assessment-including neuropsychological tests, medical imaging, and contemporary accounts of the injury—was quite limited.

Hyer and Brandon suggest that it would have been useful to have measures of the brain injury itself, such as the Post Concussion Symptom Scale, or biomarkers such as target proteases in glial cells. They suggest that comprehensive neuropsychological testing could have been used to identify neuropsychological deficits, as well as compensatory strengths.

Webb’s comments are similar, pointing out that findings from neuroimaging, neurological and neuropsychological examinations, as well as medical records, would have been advantageous. She also suggests that medical tests might also have been useful to help identify any other factors that might have been contributing to Judith’s condition.

King also contends that a full neuropsychological assessment would have been useful, to determine whether executive deficits were truly evident. In addition, he suggests that clinical data would have been useful to determine the extent to which there was an ongoing neurological basis to Judith’s cognitive problems, and the severity of these underlying pathologies.

We wholeheartedly agree that each of these measures might have been useful. As detailed below, there are many reasons why we did not engage in extensive testing or attempt to access detailed medical records, and we will consider each of these in turn.

\section{Obtaining Medical Records}

In the UK health system, it can be very difficult to track down extensive medical records 10 years after an injury, when the patient has long since been discharged. Furthermore, Judith has no recollection of who her consultants were at the time. In this era, paper records were kept 
Perspective Within a Client-Centered and Pluralistic Therapy Framework

T. Ward \& K. Hogan

Pragmatic Case Studies in Psychotherapy, http://pcsp.libraries.rutgers.edu

Volume 11, Module 1, Article 5, pp. 55-64, 03-01-15 [copyright by authors]

locally and archived, with no central database or records. Local health practitioners would receive only a written summary at the time of discharge.

At several points we did consult with Judith's health practitioner, especially at times where we felt there was some significant risk. The general practitioner did not point to any other relevant health factors that he was aware of at this time.

\section{The Setting in Which the Therapy Took Place}

The therapeutic work with Judith took place within an outreach community counseling center, based in a university. It was not a rehabilitation setting. Thus while the authors acknowledge that long-term therapy with head injured clients' needs to address their ongoing daily needs and concerns, this was not necessarily the main initial focus.

\section{Presentation with Acute Trauma}

Judith initially presented with acute trauma, following the recent collapse of her marriage. This was the initial focus of the intervention. Knowing Judith had a history of head injury, the authors thought through the possible implications and complications of this.

It is worth reminding ourselves that the therapeutic approach was initially the clientcentered approach. This particular way of working often raises the question of sufficiency in people's minds, that is, can this be enough? We are aware that this question is highly salient when applied to people with head injury. Carl Rogers, the developer of client-centered therapy, proposed that individuals have a biological tendency to move towards growth, which he termed the "actualizing tendency." In terms of the optimal attitude of the counselor, Rogers suggested "the counselor chooses to act consistently upon the hypothesis that the individual has a sufficient capacity to deal constructively with all those aspects of his life which can come into conscious awareness” (Rogers, 1951, p. 24 ). In other words, with every new client, counselors adopt an attitude that this client can potentially deal constructively with the issues they become aware of. Many counselors who work with this approach with non-head-injured clients will become aware as they gain experience that this hypothesis will hold true for a great many of them. On the other hand, with head injured clients, whether it will hold true is less certain, and a great deal more clinical research with client-centered therapy is needed with this population. As we suggested in our case study (Ward \& Hogan, 2015), we do not know at this time the extent to which this will hold true, or whether a certain level of severity may prevent this being a useful approach for some clients. In any event, with Judith, we feel client-centered therapy was particularly helpful.

\section{Working Within Cooper and McLeod's Pluralistic Model}

The client-centered approach we adopted was embedded within the pluralistic framework of Cooper and McLeod (2011). This framework allows the therapist to use different, sometimes contrasting approaches, to facilitate client growth, within a collaborative relationship. The goals to be addressed are discussed and negotiated with the client. Once the goals are established, the tasks that will lead to accomplishing the goals, and the methods that will be used to accomplish 
Perspective Within a Client-Centered and Pluralistic Therapy Framework

T. Ward \& K. Hogan

Pragmatic Case Studies in Psychotherapy, http://pcsp.libraries.rutgers.edu

Volume 11, Module 1, Article 5, pp. 55-64, 03-01-15 [copyright by authors]

these are mutually agreed. In the case of Judith, the initial goal, which was very quickly established, was to allow her to be able to live with the personal pain and anguish she felt at being abandoned by her husband; the task was to explore her feelings and thoughts around this; and the method employed was client-centered personal exploration. The pluralistic framework is explicit that the client's goals are constantly reviewed and, if necessary, redefined. Thus as soon as the intensity of Judith's emotional pain began to subside and metamorphose, other current goals came to the fore, such as developing the self-belief that she could cope by herself with her everyday household management. At the forefront of this was how to cope with what Judith perceived as an avalanche of daily correspondence pouring through her door.

We were aware at an early stage that Judith's problems had at some point in the past been characterized as "executive" in nature. Judith had good recollection of this from the original neuropsychological report, which had been written for insurance purposes. Unfortunately, this report was no longer available. Furthermore, the assessment and report had been written some 10 years previously. However, we considered that Judith's presentation was very reminiscent of executive difficulties. For example, her repetitive speech patterns reminded us of an early case history published by the first author (Alderman \& Ward, 1991). It was also very evident that Judith's descriptions of her everyday difficulties resonated with executive deficit explanations. For example, her inability to return to work was due to the fact that she could not plan and schedule her day. Furthermore, core activities she needed to routinely deal with in a problemsolving fashion, often with some degree of novelty, completely perplexed her. She found she was asking for step-by-step guidance throughout the day, preventing other colleagues from getting on with their work.

Given the hypothesis that Judith had ongoing executive difficulties 10 years after her head injury, we decided to do some minimal neuropsychological testing to see if this was consistent with such an explanation. Using the Wechsler Adult Intelligence Scale version 3 (Wechsler, 2000), we administered the vocabulary subtest so that we could estimate Judith's premorbid functioning; the digit span subtest, because the backwards digit span heavily relies on executive aspects of memory; and the block design subtest, because it is seen as a classic test of executive function. Judith was satisfied with the rationale for this and she was interested to see how well she did. She also derived some satisfaction from the results in that it helped her to put some of her difficulties into perspective. We also discussed this case with Professor Nick Alderman, a clinical director in a brain injury service program in Northhamptonshire, England. Alderman pointed out to us that executive deficits in very high functioning individuals are often not as evident in psychometric tests as they are in complex, real-life behaviors, hence his preference for ecological data (Alderman et al., 2003). Alderman's view was that Judith's case was consistent with classic cases of high functioning people with executive deficits.

Moreover, Judith was not willing to countenance extensive neuropsychological testing. We did in fact offer Judith the opportunity to take a number of other possibly helpful tests, such as the dual task element of the Test of Everyday Attention (Robertson et al., 1994). The first author (TW) was very aware that this could be useful, being a co-author of this test battery. To insist that Judith take additional tests would have been highly inconsistent with the pluralistic 
Perspective Within a Client-Centered and Pluralistic Therapy Framework

T. Ward \& K. Hogan

Pragmatic Case Studies in Psychotherapy, http://pcsp.libraries.rutgers.edu

Volume 11, Module 1, Article 5, pp. 55-64, 03-01-15 [copyright by authors]

framework we were employing. Recent research on the pluralistic approach suggests that the highly collaborative nature of the framework produces high client satisfaction and acceptability (Cooper et al., in press).

In sum, we agree with the idea of the commentators that if the logistical and clinical conditions had been more favorable, more testing data and medical records would have been helpful in Judith's case. However, as previously indicated, obtaining original data 10 years post injury was problematic. Furthermore, pushing the client through extensive neuropsychological assessment would have been counterproductive in terms of acceptability, counter to the pluralistic ethos of the work, and ultimately probably not that helpful to the client, given the opportunities for extensive ecological exploration of the client's issues in situ.

\section{WHAT QUESTIONS REMAIN?}

As indicated above, we do not know the precise neuropsychological profile of Judith. However, we do believe that she was severely affected in the executive functioning domain, 10 years after her original injury. The evidence for this is her very high level of pre-morbid functioning, her very low scores on block design, and her reduced score on digit span. Coupled with this is extensive evidence from her attempts to return to work, carry out household tasks, and manager her day-to-day affairs. In the latter case, the difficulty was not about knowing the nature of some of the tasks she faced, such as the need to pay tax on her vehicle, but the ability to plan and order the various steps required to accomplish these tasks. As Alderman et al. (2003) have pointed out, psychometric test data is not always the best indicator of executive deficits, and real life observation can be much more useful. We note the similarities between Alderman et al.'s (2003) multiple errands task, and many of the day-to-day household management issues faced by Judith.

Related to the above, we do not know the exact severity of Judith's head injury, or whether pathological changes to the brain would still be evident 10 years later. This leads King (2015) to question whether Judith should be considered as similar to an earlier case report (King, 2002). In relation to this, we would put forward the following observations.

First of all, as noted by King (2015), it appears there was a considerable period of anterograde amnesia. This suggests a moderate-to-severe injury. Consistent with this is the significant amount of compensation she was initially paid for her disability together with her disability pension. The compensation was not as high as one might predict for someone suffering such long term consequences, but unfortunately such figures do not always seem to adequately reflect the ability to return to a role fully commensurate with the previous role in terms of pay and esteem. This has frequently been noted in relation to executive deficits (Alderman et al, 2003).

We note Webb's questioning some aspects of the plausibility of Judith's account, in that some kind of facial agnosia seems highly unlikely. We agree. In fact we never thought that was the case, or would have suggested it. Rather, Judith's difficulty in recognizing her neighbors was part of a prolonged period of confusion and anterograde amnesia. 
Judith's account of the actual incident when she was injured is inconsistent with the above. She suggests that she was not unconscious for very long, and was mobile by the time the ambulance arrived. However, this account is not from Judith's actual memory. She has no personal recall of the actual incident; and her account is based entirely on what she thinks she has been told afterwards.

To summarize this issue, we believe that the evidence in this case is consistent with Judith having received a significant head injury, causing her to have to give up her work and having to deal with residual executive deficits 10 years later.

Other questions remain about the precise mechanisms of psychotherapy when working with head-injured clients. According to Rogers (1951), client-centered therapy works through the client being involved in an accepting emotional therapeutic relationship with the counselor, and the fact that there is a biological predisposition to access growth processes and move forward in a way that resolves difficulties. There are other contemporary views about how such processes work with trauma (e.g., Joseph, 2005). How might this be affected by the severity and nature of an injury? How do other therapies work with such populations, for example, to what extent are processes such as "transference" (Lemma, 2003) or "maladaptive schemas" (Young et al., 2003) likely to work in the same way with head-injured populations, compared to neurological client groups?

\section{WHAT IS THE OVERALL CONTRIBUTION OF THE CASE STUDY WITH JUDITH?}

Consistent with the views of the various commentaries, we believe that the case of Judith has illustrated how clients with neuropsychological deficits can be helped in therapy using an integrated, context-sensitive approach. We believe that her case demonstrates that such clients can be helped to deal with significant trauma using a client-centered approach, and this can then allow their other daily-living problems to be addressed using cognitive training. We also believe that this case has demonstrated how the pluralistic framework, which advocates a collaborative working relationship with clients, can be highly effective in addressing their concerns. Given a long-term commitment to clients, which allows for thorough functional assessment of their environment and difficulties, extensive neuropsychological testing may be helpful, but not critical.

Finally, we would endorse King's view (Tyerman \& King, 2008) that much more extensive service provision is urgently needed for clients such as Judith. There was no possibility for Judith to access this kind of support in her locality, except through our university-based service. Eventually, when she had funds released as part of the divorce settlement, she was able to access a local, voluntary, head injury support service. We believe that it is therefore timely that neuropsychological competencies have been added to the training requirements for counseling psychologists within the United Kingdom (British Psychological Society, 2014). 
Perspective Within a Client-Centered and Pluralistic Therapy Framework

T. Ward \& K. Hogan

Pragmatic Case Studies in Psychotherapy, http://pcsp.libraries.rutgers.edu

Volume 11, Module 1, Article 5, pp. 55-64, 03-01-15 [copyright by authors]

\section{REFERENCES}

Alderman, N., Burgess, P.W., Knight, C., Henman, C. (2003). Ecological validity of a simplified version of the multiple errands shopping test. Journal of the International Neuropsychological Society, 9, 31-44.

Alderman, N., \& Ward, T., (1991). Behavioural treatment of the dysexecutive syndrome: Reduction of repetitive speech using response cost and cognitive overlearning. Neuropsychological Rehabilitation, 1, 65-80.

British Psychological Society (2014). Standards for the accreditation of doctoral programmes in counselling psychology. Leicester: British Psychological Society.

Carruthers, B. M., van de Sande, M. I., De Meirleir, K. L., Klimas, N. G., Broderick, G., Mitchell, T., Staines, D., Powles, A. C. P., Speight, N., Vallings, R., Bateman, L., Baumgarten-Austrheim, B., Bell, D. S., Carlo-Stella, N., Chia, J., Darragh, A., Jo, D., Lewis, D., Light, A. R., Marshall-Gradisbik, S., Mena, I., Mikovits, J. A., Miwa, K., Murovska, M., Pall, M. L. \& Stevens, S. (2011), Myalgic encephalomyelitis: International Consensus Criteria. Journal of Internal Medicine, 270, 327-338.

Cook, D.B., Lange, G., DeLuca, J., \& Natelson, B.H. (2001). Relationship of brain MRI abnormalities and physical functional status in chronic fatigue syndrome. International Journal of Neuroscience, 107, 1-6.

Cooper, M., \& McLeod, J. (2011). Pluralistic counselling and psychotherapy. London: Sage.

Cooper, M., Wild, C., van Rijn, B., Ward, T., McLeod, J., Cassar, S., Antoniou, P., Michael, C., Michalitsi, M., Shreenath, S. (in press). Pluralistic therapy for depression: Acceptability, outcomes and helpful aspects in a multi-site trial. Counselling Psychology Review.

Gracey, F., Palmer, S., \& Ross, B. (2008). "Feeling Part of Things”: Personal construction of self after brain injury. Neuropsychological Rehabilitation, 18, 627-650.

Hyer, L. (1994). Trauma victim: Theoretical issues and practical suggestions. New York: Taylor \& Francis.

Hyer, L., \& Brandon, B. (2015). Perspectives on the case of "Judith." Pragmatic Case Studies in Psychotherapy, 11(1), Article 3, 26-41. Available:

http://hdl.rutgers.edu/1782.1/pcsp_journal

Joseph, S. (2005). Understanding post-traumatic stress from the person-centred perspective. In Joseph, S. and Worsley, R. (Eds.) Person-centred psychopathology: A positive psychology of mental health. Ross-on-Wye: PCCS Books.

King, N.S. (2002). Perseveration of traumatic re-experiencing in PTSD: A cautionary note regarding exposure based psychological treatments for PTSD when head injury and dysexecutive impairment are also present. Brain Injury, 16, 65-74.

King, N.S. (2015). Providing psychotherapy to people with neuropsychological impairment: Complexities and issues raised by the case of 'Judith.' Pragmatic Case Studies in Psychotherapy, 11(1), Article 2, 21-25. Available: http://hdl.rutgers.edu/1782.1/pcsp_journal

Lemma, A., (2003). Introduction to the practice of psychoanalytic psychotherapy. London, New York: Wiley.

Lorusso, L., Mikhaylova, S.W., Capelli, E., Ferrari, D., Ngonga, G.K., \& Ricevut,i G. (2009). Immunological aspects of chronic fatigue syndrome. Autoimmunne Review, 8, 287-91. 
Perspective Within a Client-Centered and Pluralistic Therapy Framework

T. Ward \& K. Hogan

Pragmatic Case Studies in Psychotherapy, http://pcsp.libraries.rutgers.edu

Volume 11, Module 1, Article 5, pp. 55-64, 03-01-15 [copyright by authors]

Prigatano, G.P. (1986). Psychotherapy after brain injury. In G.P. Prigatano (Ed.)., Neuropsychological rehabilitation after brain injury, pp. 67-69. Baltimore: John Hopkins University Press.

Robertson, I.H., Ward, T., Ridgeway, V., \& Nimmo-Smith, I. (1994). The test of everyday attention. London: Pearson.

Rogers, C. R. (1951). Client-centred therapy. London: Constable.

Tyerman, A. \& King, N.S. (2008). Community rehabilitation. In A. Tyermann \& N.S. King, (Eds.). Psychological approaches to rehabilitation after traumatic brain injury, pp. 6590. Oxford: Blackwell.

Ward, T., Hogan, K., (2009). A trial of client-centred counselling over the telephone for persons with ME. Counselling Psychology Review, 24, 34-41.

Ward, T., \& Hogan, K. (2015). Using client-centered psychotherapy embedded within a pluralistic integrative approach to help a client with executive dysfunction: The case of "Judith." Pragmatic Case Studies in Psychotherapy, 11(1), Article 1, 1-20. Available: http://hdl.rutgers.edu/1782.1/pcsp_journal

Ward, T., Hogan, K., Stuart, V., \& Singleton, E., (2008). The experiences of counselling for persons with ME. Counselling and Psychotherapy Review, 8, 73-79.

Webb, N (2015). The case of "Judith": A neuropsychologist's perspective. Pragmatic Case Studies in Psychotherapy, 11(1), Article 4, 42-54. Available: http://hdl.rutgers.edu/1782.1/pcsp_journal

Wechsler, D. (2000). The Wechsler Adult Intelligence Scale version 3. London: Pearson.

Young, J.E., Klosko, J.S., \& Weishaar, M.E. (2003). Schema therapy: A practitioner's guide. New York, London: Guilford Press. 